\title{
Differences in the progress of the biopesticide revolution between the EU and other major crop growing regions
}

Running title: The differences in biopesticide revolution

\author{
Adalbert Balog, ${ }^{1 *}$ Tibor Hartel, ${ }^{2}$ Hugh D. Loxdale, ${ }^{3}$ Kenneth Wilson ${ }^{4}$ \\ ${ }^{1}$ Department of Horticulture, Faculty of Technical and Human Science, Sapientia Hungarian \\ University of Transylvania. 1/C Sighisoara Street, Corunca/Tg. Mures, Romania. \\ ${ }^{2}$ Department of Environmental Science, Faculty of Art and Science, Sapientia Hungarian University \\ of Transylvania, 4 Turzi Street, Cluj-Napoca, Romania. \\ ${ }^{3}$ School of Biosciences, Cardiff University, The Sir Martin Evans Building, Museum Avenue, Cardiff, \\ Wales, CF10 3AX, UK. \\ ${ }^{4}$ Lancaster Environment Centre, Lancaster University, LEC Building, LA1 4YQ Lancaster, UK.
}

*Correspondence to: adalbert.balog@ms.sapientia.ro

Correspondence Address: Department of Horticulture, Faculty of Technical and Human Science, Sapientia Hungarian University of Transylvania. 1/C Sighisoara Street, Corunca/Tg. Mures, Romania. Tel: 0040740562240, Fax: 0040265206211

\begin{abstract}
BACKGROUND: The five year value in the compound annual growth rate of the biopesticides sector is predicted to be $16 \%$ by 2017 and to produce a global market worth
\end{abstract}

This article has been accepted for publication and undergone full peer review but has not been through the copyediting, typesetting, pagination and proofreading process, which may lead to differences between this version and the Version of Record. Please cite this article as doi: 10.1002/ps.4596

This article is protected by copyright. All rights reserved. 
\$US 10 billion. Despite this, several impediments occur within the EU that negatively influencing biopesticide research and innovation.

RESULTS: At present, there are fewer biopesticide-active substances registered in the EU compared to the USA, India, Brazil and China. The relatively low level of biopesticide research in the EU $(6,880$ ISI papers) versus the USA $(18,839)$, India $(9,501)$ and China $(7,875)$ relates to the greater complexity of EU-based biopesticide regulations compared to these other countries. In this light, it is worth noting that tensions may exist between regulators that emphasise the beneficial nature of biopesticides in environmentally-friendly crop management, and those that adopt a more technologically-based approach dependent on a chemical pesticide-driven model.

CONCLUSION: compared to the other aforementioned countries, far fewer biopesticide products are available in the EU market, mainly as a direct result of the severe regulatory factors present there. The extent to which this trend will continue depends largely on a range of interacting political and/or regulatory decisions that influence environmentally-friendly agricultural industries.

Keyword: Environmentally-friendly agriculture, political decisions, environmental laws, pesticide laws, biopesticide research

\section{Introduction}

Crop production currently represents about 813.5 million tonnes worldwide ${ }^{1}$. Global changes, including extreme variations in climatic conditions, are highly likely to affect agricultural 
production, thereby representing a challenge for global food security ${ }^{2}$. Outbreaks of herbivorous insects and mites, plant diseases caused by plant pathogens (viruses, bacteria, phytoplasma and funguses) and weeds may become more frequent in the face of global change, representing a major impediment to crop production. However, as a result of the evolution of pesticide resistance in the last 50 years or so, many of these pests (including weeds and diseases) are difficult to control. The damage caused by insects and mites ranges from $8-23 \%$ in the USA with an estimated loss of some $5-15 \%$ from the total of SUS 200 billion in revenue each year ${ }^{3-5}$. Invasive pests represent new types of threats and challenges as global trade expands and the climatic conditions shift ${ }^{6,3,4}$. Recent estimates suggest that the losses of crop yield caused by invasive pests will increase to $25 \%$ in the EU by $2080^{5}$. The excessive use of chemical plant protection products to control arthropods, diseases and weeds represents a further challenge because of accumulation of toxins in the ecosystem and food, economic and cultural constrains, accessibility and availability of environmentallyfriendly compounds, and regulation at the national level ${ }^{2}$. Developing and using effective and context-placed biological compounds (biopesticides) and adopting agricultural production strategies that are resilient to the challenges imposed by globalization should be a major task for both governments and industry alike ${ }^{6-11}$. Yet this does not seem to be happening, certainly within the EU. Here we compare the pesticide related regulations, the environmental regulations and the outcomes of research and innovation (measured by the number of published peer reviewed papers available via the Web of Science) in five globally important regions of crop production (EU, USA, India, Brazil and China) between the years 2000-2015. We hypothesise that differences in regulations may exists between countries/regions, which in turn may - or indeed does - differentially influence biopesticide research and its application.

This article is protected by copyright. All rights reserved. 


\section{Data collection and interpretation}

There are several definitions of what constitutes a biopesticide, hence the terminologies used can be confusing. Scientific references describe and discuss a broad group of agents and in this context we define biopesticides as mass produced, biologically-based agents used for the control of plant pests, including weeds, bacteria, fungi, insects, nematodes and mites ${ }^{7}$. This definition covers not only the active ingredient of a biopesticide but also the manner in which it is applied. Accordingly, biopesticides can be divided into two sub categories: (1) living organisms including micro-organisms (insect baculoviruses, beneficial bacteria and fungi) and (2) naturally occurring substances which comprise plant extracts and semiochemicals (insect pheromones) ${ }^{6,12}$.

The country-based regulations and governmental decisions that involve pesticide and environmental regulations adopted between the years 2000-2015 were searched using a newly developed data mining software (DataSEE). Laws that met the following criteria only were considered: (i) they were passed by the EU Commission, the United States Congress, the Indian and Brazil Federal Governments, and Chinese Congress; and (ii) pertain to the regulation of the interaction of humans with the natural environment with direct or indirect reference to given pesticide usage and the effects thereof. The Ministry of Agriculture and Ministry of Environment regulations of the countries-regions so investigated were carefully searched. Also particular country regulations (i.e. in EU countries) by its responsible Ministries were searched separately and the relevant laws duly selected. The country-based regulations and governmental decisions together with social and economic factors were considered for conceptual modelling. Because several local decisions cannot be found online, methods of how local authorities handle files, how such decisions require additional processes, how much local authorities of each country support the biological control sector, and how they evaluate risks are difficult to assess; therefore such aspects are discussed but 
seemingly were considered as selection and detection problems. To link drivers of biopesticide research and usage, three major factors were considered by us - namely social, economic and regulatory factors in pesticides and environment, respectively. The model fits within the DPSIR (Driving force-Pressure-State-Impact-Response) framework for reporting on environmental issues, thereby facilitating the development of relevant social and economic actions and policy actions ${ }^{13}$. Hence, linkage to EU, US, Indian, Brazilian and Chinese biopesticide regulatory factors is involved in our model and all these aspects have been carefully considered for each global region separately. Because certain of the factors considered (especially social and economic) are highly unpredictable, some of the linkages illustrated should also be treated as hypotheses for future testing. Next, a comprehensive analyses of scientific papers from EU countries, the US, India, Brazil and China were performed and the number of scientific publications on biopesticides collected from Thomson Web of Science between the years 2000-2015. Data were gathered using the same data mining software. In total, 47,334 papers were analysed and followed three steps: Firstly, authors' affiliations in the aforementioned five main areas were selected. The following selection and detection biases were considered: When joint authorship was detected, the corresponding authors and their personal contribution were compared by area. If these two reached $\geq 70 \%$ (i.e. the corresponding author was from the EU and the total author contributions of a given paper attained $70 \%$ were from the EU), the paper was included within the EU published paper cohort. This was the case for $10 \%$ of the papers, mostly as joint contributions between the EU and US-affiliated authors. Only 4\% were as joint contributions between the EU or the US and India and about $5 \%$ between China and the EU and USA respectively, and $\leq 2 \%$ between Brazil and other countries. Secondly, the founding authorities were selected and compared and papers affiliated by country according to the $70 \%$ representation procedure, as mentioned above. Lastly, authors' affiliations and the location of 
the founding authorities were compared and papers were carefully assigned again to the EU, US, India, Brazil and China. This last selection has biases relating to the quality of the papers examined. Thus in our analysis, the classification criteria of Q and D levels (Scimago Journal Ranking) were considered between regions. However, whilst the highest quality papers were detected from the USA, their sheer number was found to artificially inflate the number of papers thus recorded during sampling and reporting, a trend also observed for some other regions. In light of this, such an approach for assessing paper quality was not considered.

\section{Biopesticide use, research and regulations in the EU, USA, India, Brazil and China}

Worldwide there are about 1,400 biopesticide products (about 1,000 active ingredients) sold annually ${ }^{14-16}$, representing an amount of approximately $2.5 \%$ of the total pesticide market ${ }^{16}$. At present, there are 68 biopesticide active substances registered and commercially used in the EU (i.e. in the UK there are only five microbial products currently available on the market, whereas around ten are available in Germany, and 15 in France and The Netherlands $)^{14,17}$. Biopesticide commercialisation and their use within the EU falls under the Plant Protection Products (PPP) legislation ${ }^{1,2}$. In the UK, the Pesticides Safety Directorate (PSD) regulates both chemical and biopesticides, and their commercialization use is directed by both national and EU level arrangements ${ }^{2,17,11}$. Between 2000-2015, the EU adopted 14 regulations concerning biopesticide authorization and use, whilst in contrast, 181 environmental regulatory acts and laws were passed that directly or indirectly relate to environmental friendly pesticide use ${ }^{1,18}$.

In the US, the biopesticide portfolio comprises 400 registered biopesticide-active ingredients $5,6,19,20$. In that country, the Federal Insecticide, Fungicide and Rodenticide Act 
(FIFRA) only requires that the US Environmental Protection Agency (EPA) evaluate the proposed biopesticide to assure that its use will not pose unreasonable risks to human health and the environment before it can be released and marketed. Altogether, four major Federal regulations were proposed between 2000-2015 and codified concerning biopesticide authorization into the Code of Federal Regulations (CFR). Another 20 federal acts with relevance to environmental protection and sustainability related to environmental friendly pesticide use were also adopted in the same period.

The total number of biopesticide products reached around 1,000 in India ${ }^{12,21}$. India follows the consensus adopted by the USA that biopesticides are not toxic and hence only eight environmental regulatory acts and laws on environmental friendly pesticide use have so far been adopted between 2000-2015 ${ }^{21}$.

The biopesticide sector in Brazil has increased by two orders of magnitude over the past five years ${ }^{9,11,16}$, and with some 100 active ingredients registered ${ }^{11,16}$. Biopesticide evaluation and registration is controlled by three Brazilian governmental agencies: The Ministry of Agriculture and Supply - MAPA, the National Health Surveillance Agency (affiliated to the Ministry of Health) and The Brazilian Institute for the Environment and Natural Resources (affiliated to the Ministry of Environment) ${ }^{11}$. Five biopesticide regulation laws, including registration laws, and six environmental regulation laws encouraging environmentallyfriendly pesticide use were adopted over the period in question, 2000-2015 ${ }^{16}$.

In China by way of contrast, the number of biopesticides registered over the past five years increased by $16 \%$, whereas growth of chemical products was just $3 \%{ }^{8,14}$. Over $60 \%$ of the biopesticide market in China is dominated by US enterprises. The number of active ingredients registered is $111^{3,11}$. The Institute for the Control of Agrochemicals affiliated to the Ministry of Agriculture is responsible for registration, quality control, bioassay and residue monitoring of pesticides ${ }^{22,}{ }^{23}$. Two biopesticide regulation laws and eight 
environmental regulations in environmental friendly pesticide use were adopted between $2000-2015^{22}$.

In terms of biopesticide development, registration and application, contradictions are created between countries because, whilst a high number of environmental regulations in the EU refer to environmental friendly pesticide use, the rigid application of the biopesticide registration system is considered by many in the biopesticide industry to be an impediment and unfriendly environment for this sector to develop (Figure 1). Comparing data on the published peer reviewed scientific papers on biopesticides across the five regions examined shows a constant increase over the period 2000-2015, with the largest number of papers published in the USA $(18,839)$, followed by India $(9,501)$, China $(7,875)$, the EU $(6,880)$ and Brazil $(4,239)$ (Figure 2). The quality of papers (in terms of journal impact points and citations) increased as the number of papers increased; therefore this parameter has not been considered in our further interpretations. A further aspect which must be considered is that several commercial developments are not published, whilst some of the publications from India, China and Brazil may cover agents which have been previously investigated in the USA and Europe. Even so, it is worth noting the large differences between regulatory approaches in India, Brazil, China and to some extent the USA emphasise the beneficial effects of biopesticides and encourages their use in ecologically-based Integrated Pest Management (IPM) strategies versus those in the EU, the latter requiring a more technological approach, one that follows and regulates a chemical-pesticide driven development model. This particular contradiction is also reflected in the requirement of efficacy testing for biopesticides and the time taken for full registration. In the EU, two planting seasons are required for field tests and another 29 months for full registration if no additional data are requested, otherwise the whole process may last 5-7 years. There is no requirement for testing at a national level in the USA (but this differs among States), so the 
time for registration is 18 months. Two planting season at three test sites are required in India, and 24 months for full registration. One planting season and 18 months are required in Brazil, while two planting seasons at four to five test sites and 12 months for registration is required in China ${ }^{11}$.

\section{Aspects of EU regulations}

Within the EU, biopesticide registration files are first submitted to a Rapporteur Member state, which produces a Draft Assessment Report (DAR). Thereafter, the decision is taken at EU level whether the compound will be listed according to EC 1107/2009. According to this regulation, biopesticides should only be included in plant protection products where it has been demonstrated that they present a clear benefit for plant production and at the same time, do not pose any harmful effects on human or animal health, nor any unacceptable effects on the environment. In order to reach the same level of protection in all Member States, the decision on acceptability or non-acceptability of such products should be taken at Community level on the basis of harmonised criteria. In addition, these criteria should be applied for the first approval of an active substance under this Regulation. Lastly, for biopesticide products already approved, the criteria should be applied at the time of renewal or review of their approval. All in all, the purpose of this Regulation is to increase the free movement and availability of such products between the Member States ${ }^{24}$.

Specific aspects of regulation EC 1107/2009: 'In the interest of predictability, efficiency and consistency, a detailed procedure should be laid down for assessing whether an active substance can be approved. The information to be submitted by interested parties for the purposes of approval of a substance should be specified. In view of the amount of work connected with the approval procedure, it is appropriate that the evaluation of such information be performed by a Member State acting as a rapporteur for the Community. To 
ensure consistency in evaluation, an independent scientific review should be performed by the European Food Safety Authority established by Regulation (EC) No 178/2002 of the European Parliament and of the Council of 28 January 2002 laying down the general principles and requirements of food law, establishing the European Food Safety Authority and laying down procedures in matters of food safety. It should be clarified that the Authority performs a risk assessment whilst the Commission should perform the risk management role and take the final decision on an active substance, ${ }^{24}$.

Although EU countries try to adopt these standards or refer to registration, differences still exist on a lower level. Critical questions include how authorities handle files, how much they support the biological control sector, and how they evaluate risks. In relation to these particular aspects, the EFSA has become a major governing player in the EU and their judgements most often result in additional requests for data, which prolongs the process and makes it more expensive.

\section{Some aspects that prolong working processes:}

1. The standard of mutual recognition means the ensuring of the free movement of biopesticide products within the Community. To avoid any duplication of work, to reduce the administrative burden for industry and for Member States, authorisations granted by one Member State should be accepted by other Member States where agricultural, plant health and environmental (including climatic) conditions are comparable. This process is, however, currently lasting several years and there is no clear harmonization between the professional authorities of the various EU member countries.

2. Another aspect is that according to regulations the Community should be divided into zones with comparable environmental conditions in order to facilitate such mutual recognition. Even so, this has not been considered until now in several EU 
member states. According to the regulation 'environmental or agricultural circumstances specific to the territory of one or more Member States might require that, on application, Member States recognise or amend an authorisation issued by another Member State, or refuse to authorise the plant protection product in their territory, where justified as a result of specific environmental or agricultural circumstances or where the high level of protection of both human and animal health and the environment required by this Regulation cannot be achieved, ${ }^{24}$.

3. The general process of registrations is long. The registration of biopesticide products lasts on average seven years in the EU. In comparison, to register biocontrol agents with the Environmental Protection Agency (EPA) in the USA, the body in charge of such regulation, the process lasts on average only two years ${ }^{25}$.

\section{Particular products registration requires unnecessary and expensive procedures.}

In the case of several micro-organisms that provide high levels of control against plant pests and diseases, these are required within the EU to undergo comprehensive risk assessment such that producers often submit extensive dossiers on their safety. This procedure is based on rules originally developed for synthetic pesticides. Although the EU directive encourages fast implementation of micro-organisms, product registration is still time consuming and costly, thereby discouraging the introduction of such products into the market. For example, insect baculoviruses are safe to vertebrates and highly host specific. However, to use them as biological control agents within the EU, costly registration procedures are required at member state level too, thereby making the registration process extremely slow. Other examples include sex pheromones that are natural odour signals produced by female insects to attract males. When used in "mating disruption" or "mass trapping" schemes to effect plant protection these chemical substances must be also registered in the EU, 
as must also several plant extracts normally used in food, cosmetics and medicine when employed as plant protection agents ${ }^{25}$.

\section{Proposals that will accelerate processes:}

\section{There are EU organizations (e.g. REBECA - Regulation of Biological Control}

Agents) supporting action to review the legal procedures involved in product registration of biocontrol agents and offer possibilities to speed up and evaluate their potential risks, as well as comparing the regulations in the EU and the USA, and thereby propose better alternatives than those presently existing. Altogether these approaches offer less bureaucratic and more efficient regulation procedures, whilst at the same time maintaining the same level of safety for human health and the environment and accelerating market access of these products ${ }^{25,27,}$ ${ }^{28}$. Some special aspects considered important to accelerate biopesticide availability within the EU include:

i. Improving the implementation of regulations. Short-term implementation would be possible for proposals which are not controversial and require no changes of legislation. In this context REBECA brings together stakeholders from regulatory authorities, including in terms of policy, the biopesticide industry, scientists, and environmental agencies to share knowledge and experience in regulation and safety. The broad aim is to identify those fields that need further assessments and regulation, and those that can be adopted by each member state as quickly as possible. A major goal is to form a network between EU countries bringing together the market, science and policy thereby forming a critical mass necessary to speed up biopesticide regulation procedures. The results could serve as a basis for reviewing current legislation and guidance for biopesticides ${ }^{27,28}$.

ii. Accelerating assessment of the potential impact of the products. The re-evaluation of low risk products may allow for alternative regulation systems to be exempted, 
whilst at the same time, potential risks and a cost-benefit analysis can also be evaluated. In a comparative analysis, REBECA attempted to weigh the benefits and risks of regulation and compared these among different groups of plant protection products $^{27,28}$. Research programs (i.e. synchronized animal testing of the products) are proposed to improve the risk assessment methodology for several biopesticde products, especially for microbials. This researches will undoubtedly help in the assessment of the risks caused by artificial application of such microbials as plant protection products. In addition, other researches need to be proposed in order to determine a clear and practicable definition for low risk products. Such a definition would help produce a more precise differentiation between biological and synthetic products serving as support in the development and regulation process $27,28,29$.

iii. Accelerating biopesticide products registration. The long and costly registration procedures are currently discouraging researchers and investors in developing low risk biopesticides. REBECA as proposed to EU and member states authorities potentially allows for the reduction of costs and time frames for registration, thereby giving biopesticides a better chance to reach the market ${ }^{28,29}$.

\section{Arguments for biopesticide use}

There are important social and institutional arguments for promoting socially attractive and environmentally-sustainable pesticides. Briefly these are:

Economic arguments: Biopesticides are more attractive than chemical pesticides. This is basically because they can make important contributions to IPM strategies and help reduce reliance on chemical pesticides; hence they may play a major role in the development of environmentally-friendly agricultural practices. There is also strong economic growth in the 
biopesticides market; the biopesticides sector currently has a five-year compound annual growth rate of $16 \%$ (compared with $3 \%$ for synthetic pesticides), and which is expected to produce a global market of \$US 10 billion by $2017^{6,12,14,17,19}$.

Environmental arguments: The use of biopesticides is often compatible with environmentally-friendly procedures (i.e. soil, water, forest protection) because these agents produce little or no harmful residue/s. They have relatively low or no direct impact on nontarget predatory insects and mites (natural enemies), livestock and humans, whilst the natural enemies of the pest in question can survive and reproduce in the pest population after biopesticide use, meaning that the beneficial natural enemy population (available for biological pest control) can respond to changes such as increased pest population, giving a flexible form of pest management. Furthermore, biopesticides are often developed from native biological material, whilst lastly, the overall farmland ecosystem can be managed in ways that enhance its pest control capabilities ${ }^{23}$.

Scientific arguments: By developing biopesticide science, new results are likely to serve as an important information/knowledge source in sustainable agriculture for future generations. New scientific directions in agriculture-related sciences (biotechnology and plant breeding, pest management, soil science, multitrophic interaction, ecology, environment, etc.) can then be pursued by using and understanding biopesticide effects.

\section{Conclusions}

There are marked differences between the five regions here considered with regard to the regulations concerning biopesticide use, environmental protection and scientific output of biopesticide research. The relatively low level of biopesticide research in the EU compared to the other four regions coincides with the high complexity and unnecessary long processes relating to biopesticide regulations and registration. The major challenge is how the 
authorities of the various EU member states adopt and/or synchronize regulations, handle files, how much they support the biological control sector, and how they evaluate risks. Given the important and diverse arguments surrounding biopesticides use, few related scientific analyses have so far originated within the EU, leading to the low numbers of biopesticide products currently commercialized there. All in all, the five regions considered include about half of the planet's human population (comprising some 3.7 billion people and a total GDP of $\sim$ \$US 52 trillion), and so improving biopesticide regulation and research can and undoubtedly will enhance environmentally-friendly agriculture practice and performance on a global scale. We conclude that marked differences between the regions regarding the regulations around biopesticide use, environmental protection and scientific output of biopesticide research means an uneven advancement of biopesticide technology and hence missed opportunities for improvement in terms of environmental quality.

\section{References}

1. World Agricultural Production. 2016. United States Department of Agriculture Foreign Agricultural Service Circular Series WAP 2 - 16 February 2016, 27 pp. http://apps.fas.usda.gov/psdonline/circulars/production.pdf. [accessed 13 September 2016].

2. Elbehri A. Climate change and food systems. Global assessments and implications for food security and trade. Food and Agriculture Organization of the United Nations, Rome, 2015, 356 pp. http://www.fao.org/3/a-i4332e.pdf. [accessed 2 September 2016].

3. AGROW, World Crop Protection News. World Crop Protection News, biopesticides and China specials. 40 pp. (2015). https://www.agra-net.com/agra/agrow/supplements-reports/supplements/article481781.ece. [accessed 6 August 2016].

4. Invasive Species Activities. United States Department of Agriculture Forest Service, 2015.

5. United States Environmental Protection Agency (USEPA) 2015. Agriculture and Food Supply. http://www3.epa.gov/climatechange/impacts/agriculture.html. [accessed 1 September 2016].

6. Copping L. The Biopesticides Manual. British Crop Protection Council, Farnham, UK. 1998. 333 pp. 
7. Blum B. Blocked opportunities for biocontrol. Approp Tech 29(4):56- 57 (2002). doi:e00d9186989f96782e681f52bad52d5d.

8. Chandler D, Bailey AS, Tatchell GM, Davidson G, Greaves J, Grant WP. The development, regulation and use of biopesticides for integrated pest management Philos Trans R Soc Lond B Biol Sci 366(1573):1987-1998 (2011). doi:10.1098/rstb.2010.0390.

9. Chandler D, Grant W, Greaves J, Prince G, Tatchell M. Biopesticides: The Regulatory Challenge. Warwick HRI, Wellesbourne, Warwickshire, 31 October 2007.

10. Ghini R, Hamada E, Angelotti F, Costa LB, Bettiol W. Research approaches, adaptation strategies, and knowledge gaps concerning the impacts of climate change on plant diseases. Trop Plant Pathol 37(1):5-24 (2012). doi:org/10.1590/S1982-56762012000100002

11. Verger PJP, Roobis AR. Revaluate pesticides for food security and safety. Science 341:117-118 (2013). doi: 10.1126/science. 1241572 .

12. Jarvis P. Biopesticides Trends and Opportunities. Agrow Reports DS224. PJB Publications Ltd., London. 2001, 97 pp.

13. Harrison ME. Using Conceptual Models to Understand Ecosystem Function and Impacts of Human Activities in Tropical Peat-swamp Forests. Wetlands 33:257-167 (2013). doi:10.1007/s13157-0130378-0. http://www.fs.fed.us/sites/default/files/cr-2015-report-invasive-species.pdf. [accessed 1 August 2016].

14. Meyer R. Technology options for feeding 10 billion people. Plant breeding and innovative agriculture. Science and technology. EU Parliament. $2013, \quad 211 \quad$ pp. http://www.europarl.europa.eu/RegData/etudes/etudes/join/2013/513521/IPOLJOIN ET(2013)513521_EN. [accessed 2 August 2016].

15. Wilson K, Benton T, Graham R, Grzywacz D. Pest control: biopesticides' potential Science 342:6160 (2013). doi:10.1126/science.342.6160.799-a.

16. Birkett R. Biopesticide applications boom in Brazil. 2016. https:/www.agra-net.com/agra/agrow/marketsregulatory/south-america. [accessed 12 August 2016].

17. Harris J. Chemical Pesticides Markets, Health Risks and Residues. Biopesticide Series No. 1. CABI Publishing, Wallingford, UK, 2000.

18. Gabrielsen P, Bosch P. Environmental indicators: typology and use in reporting. European Environment Agency. 2003, 20 pp. http://www.costabalearsostenible.com/ATenpdf/2. [accessed 24 August 2016]. 
19. Cory JS. Ecological impacts of virus insecticides: host range and non-target organisms. In: Environmental Impacts of Microbial Insecticides. Hokkanen MT and Hajek A (Eds). Kluwer Academic Publishers, Dordrecht, the Netherlands. 2003. 272 pp.

20. Bailey KL, Boyetchko SM, Langle T. Social and economic drivers shaping the future of biological control: a Canadian perspective on the factors affecting the development and use of microbial biopesticides. Biol Control 52:221-229 (2010). doi:10.1016/j.biocontrol.2009.05.003.

21. Biopesticides - Quality Assurance National Academy of Agricultural Science, New Delhi, December 2013.

22. Environmental Protection Law of the People's Republic of China. 2014, 15 pp. https://www.chinadialogue.net/Environmental-Protection-Law-2014-eversion. [accessed 22 August 2016].

23. Harrington R, Anton C, Dawson TP, de Bello F, Feld CK, Haslett JR, Kluváankova-Oravská T, Kontogianni A, Lavorel S, Luck GW, Rounsevell MDA, Samways MJ, Settele J, Skourtos M, Spangenberg JH, Vandewalle M, Zobel M, Harrison PA. Ecosystem services and biodiversity conservation: concepts and a glossary. Biodiv Conserv 19:2773-2790 (2010). doi:10.1007/s10531-010-9834-9.

24.http://eur-lex.europa.eu/legal-content/EN/TXT/PDF/?uri=CELEX:02009R1107-20140630\&qid $=1440753313082 \&$ from $=\mathrm{EN}$

25. http://www.rebeca-net.de/?p=160

26. http://cordis.europa.eu/result/rcn/47507_en.html

27. http://www.rebeca-net.de

28. Fjelsted A, Ehlers RU. Proposals on how to accelerate registration of biological control agents. In: Ehlers RU (ed), Regulation of Biological Control Agents. Dortrecht, Heidelberg, London, New York, Springer, 375-405 (2011)

29. Hauschild R, Speiser B, Tamm L. Regulation according to EU Directive 91/414: data requirements and procedure compared with regulation practice. In. Ehlers RU (ed), Regulation of Biological Control Agents. (2011)

\section{Figure legends}


Figure 1. Conceptual model of biopesticide research and innovation. To link drivers, four major factors were considered (social factors, economic factors, regulation factors in pesticides and environment). Arrows show directions of these drivers for each of the four factors. To better distinguish each region and driver direction, different colours for each regions are used. Wide yellow arrow represents highly negative (-), wide white arrow highly positive $(+)$ factors that influencing biopesticide research and innovations.

Figure 2. The number of scientific papers published in biopesticide technology, application and their effects in the EU, USA, India, Brazil and China between the years 2000-2015 according to ISI Web of Science. Colours are used to allow for a better separation between regions.

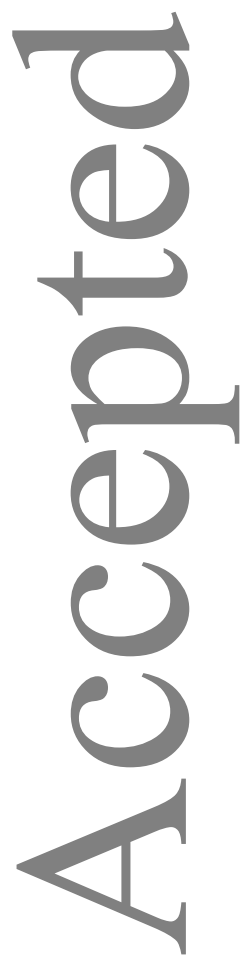

Figures 


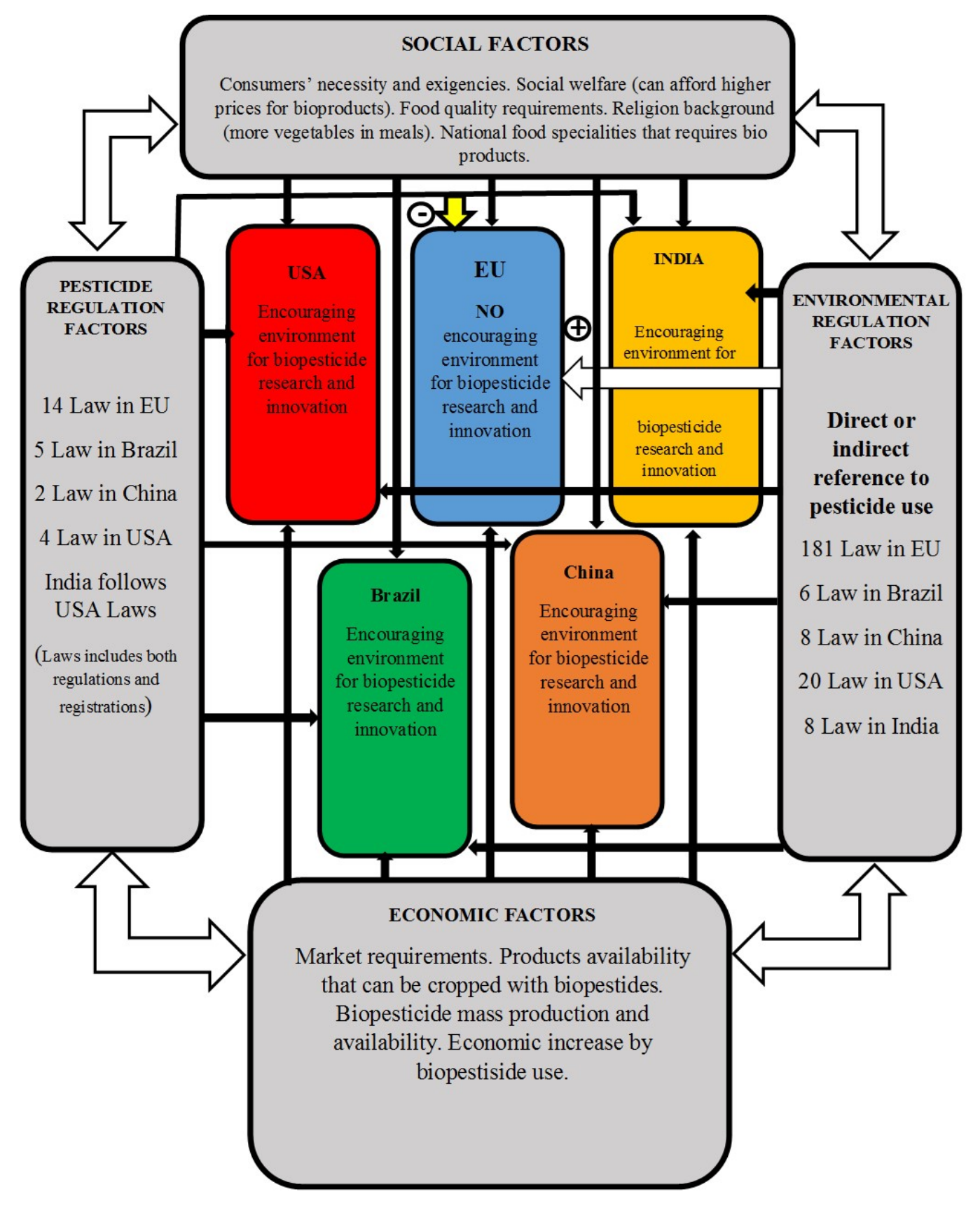

Figure 1.

This article is protected by copyright. All rights reserved. 
